\title{
Contiguous triple spinal dysraphism associated with Chiari malformation Type II and hydrocephalus: an embryological conundrum between the unified theory of Pang and the unified theory of McLone
}

\author{
Sivashanmugam Dhandapani, MCh, and Anirudh Srinivasan, MS \\ Department of Neurosurgery, Post Graduate Institute of Medical Education and Research (PGIMER), Chandigarh, India
}

\begin{abstract}
Triple spinal dysraphism is extremely rare. There are published reports of multiple discrete neural tube defects with intervening normal segments that are explained by the multisite closure theory of primary neurulation, having an association with Chiari malformation Type II consistent with the unified theory of McLone. The authors report on a 1-year-old child with contiguous myelomeningocele and lipomyelomeningocele centered on Type I split cord malformation with Chiari malformation Type II and hydrocephalus. This composite anomaly is probably due to select abnormalities of the neurenteric canal during gastrulation, with a contiguous cascading impact on both dysjunction of the neural tube and closure of the neuropore, resulting in a small posterior fossa, probably bringing the unified theory of McLone closer to the unified theory of Pang.

http://thejns.org/doi/abs/10.3171/2015.6.PEDS15179
\end{abstract}

KEY WORDS contiguous triple spinal dysraphism; split cord; myelomeningocele; lipomyelomeningocele; Chiari malformation Type II; unified theory of McLone; unified theory of Pang; congenital; spine

$\mathrm{T}$ RIPLE spinal dysraphism, which consists of 3 discrete neural tube defects with normal intervening segments, is extremely rare, with hardly any cases reported in the literature. ${ }^{11,12}$ Most such cases with myelomeningocele (MMC) could be explained by the multisite closure theory of primary neurulation..$^{13}$ The association of defective primary neurulation with Chiari malformation Type II (CM-II) was explained by the unified theory of McLone, ${ }^{5}$ implicating failure of apposition of spinal neuroceles. We report probably the first case of contiguous triple spinal dysraphism consisting of MMC and lipomyelomeningocele (lipo-MMC) centered on Type I split cord malformation (SCM I), associated with CM-II and hydrocephalus. We discuss the embryological basis and conundrum between the unified theory of Pang ${ }^{7}$ and the unified theory of McLone. ${ }^{5}$

\section{Case Report}

History and Examination

A 1-year-old girl presented with 2 swellings in her back, which were associated with increasing head size since birth. There was a history of excessive crying at the time of micturition, with delay in lower limb motor milestones. Examination revealed an upper cystic swelling that increased in size on crying, with the overlying skin papery thin, and a lower fatty swelling with a tuft of hair (Fig. 1). Spine CT/MRI studies revealed an SCM I with 2 thecal sacs and a bony spur separating them at the T12/L1 level. There was an MMC superiorly, and a lipo-MMC inferiorly tethering the cord. Brain MRI revealed hydrocephalus and CM-II (Fig. 2).

\section{Operations and Postoperative Course}

The child initially underwent right ventriculoperitoneal shunt placement. On a later date she underwent excision of the bony spur and lipo-MMC with repair of the MMC, detethering of the hemicords, and reconstitution of a single dural tube. Intraoperatively, the bony spur was observed to be wedging the superior MMC and the inferior lipoMMC. The MMC was tethering the right hemicord and the lipo-MMC was tethering the distal "Y" junction of the hemicords (Fig. 3). Postoperatively the child had mild paraparesis, which improved over a period of time.

ABBREVIATIONS CM-II = Chiari malformation Type II; lipo-MMC = lipomyelomeningocele; $\mathrm{MMC}=$ myelomeningocele; $\mathrm{SCM}=$ split cord malformation .

SUBMITTED March 27, 2015. ACCEPTED June 4, 2015.

INCLUDE WHEN CITING Published online October 16, 2015; DOI: 10.3171/2015.6.PEDS15179. 


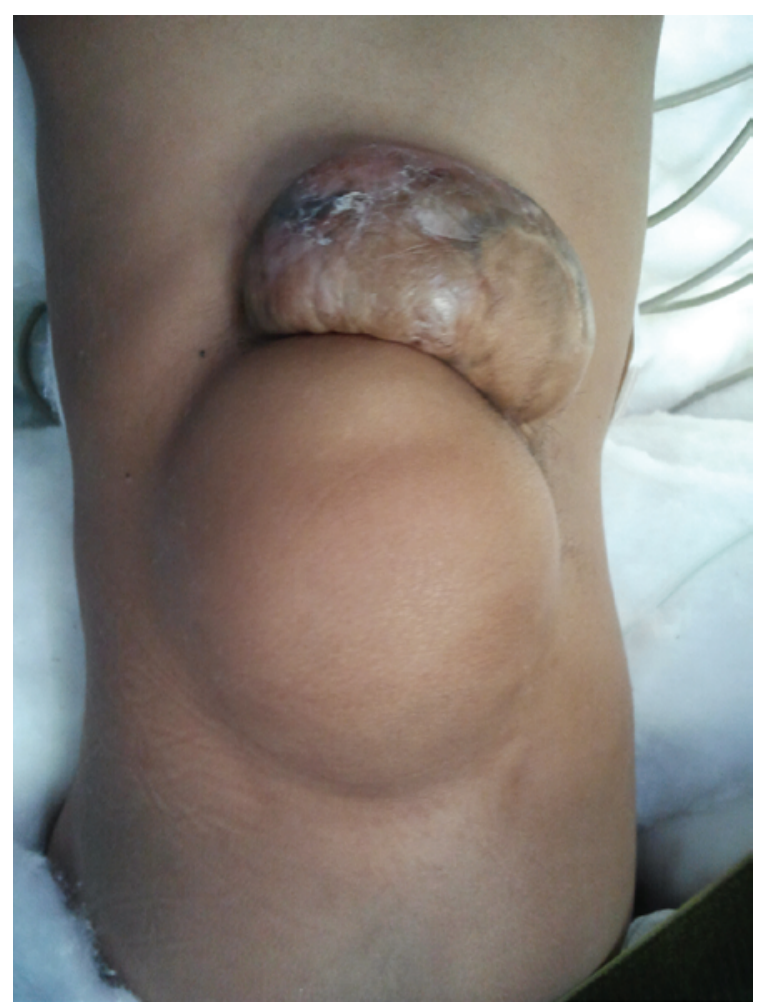

FIG. 1. Clinical photograph showing contiguous MMC and lipo-MMC. Figure is available in color online only.

\section{Discussion}

Spinal dysraphism consists of all SCMs that are due to defects in embryonic stages, from gastrulation to primary and secondary neurulation. ${ }^{8}$ Although the incidence of spinal dysraphism is approximately 1 in 1000 live births, multiple defects are extremely rare. ${ }^{1}$

The unified theory of Pang proposed a common embryogenetic mechanism at the time of gastrulation to explain the development of all SCMs? ${ }^{7}$ It speculated that an accessory neurenteric canal is formed by adhesions between ectoderm and endoderm, with the endomesenchymal tract condensing around and bisecting the developing notochord. In SCM I, the mesenchymal cells probably induce the formation of an osseocartilaginous septum dividing the spinal canal into 2 dural sheaths that have separate hemicords. However, this theory does not explain the rare association of SCM with neurulation defects or CM-II. ${ }^{2}$

Neural tube defects such as lipo-MMC and MMC arise from abnormalities of neurulation. ${ }^{1,8}$ During neurulation, following the folding of neuroectodermal plate, the formed neural tube separates from the overlying cutaneous ectoderm in a process referred to as dysjunction. For the development of lipo-MMC, McLone et al. proposed premature dysjunction of the neuroectoderm prior to the completion of the neural tube, permitting entry of mesoderm into the lumen of the still incompletely closed neural tube. ${ }^{6}$ This mesoderm subsequently differentiates into
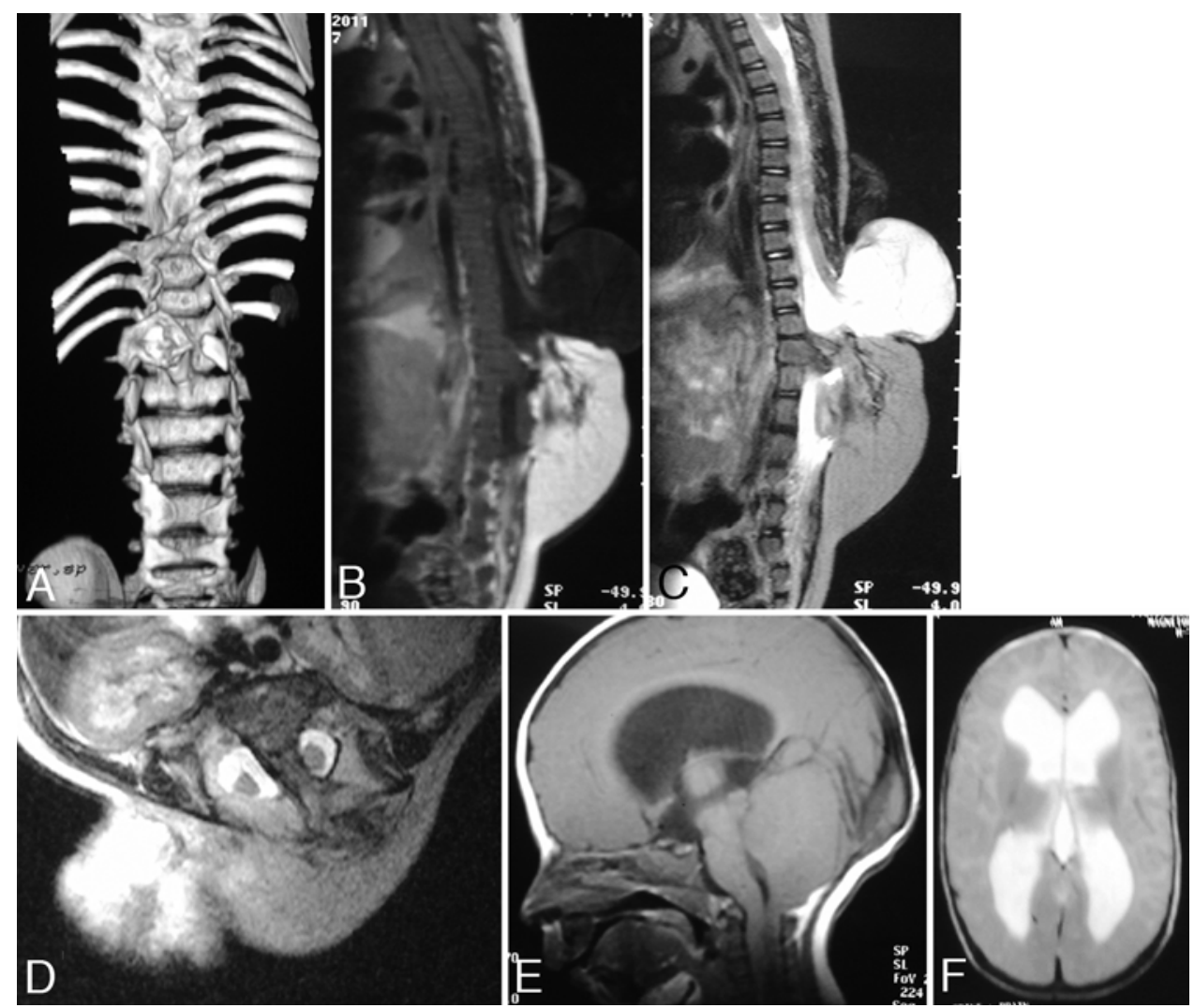

FIG. 2. Spine CT scan showing bony spur (A). T1 sagittal (B), T2 sagittal (C), and T2 axial (D) MRI studies of spine showing contiguous superior right-sided MMC and inferior lipo-MMC. T1 sagittal (E) and T2 axial (F) MRI studies of brain showing CM-II and hydrocephalus. 


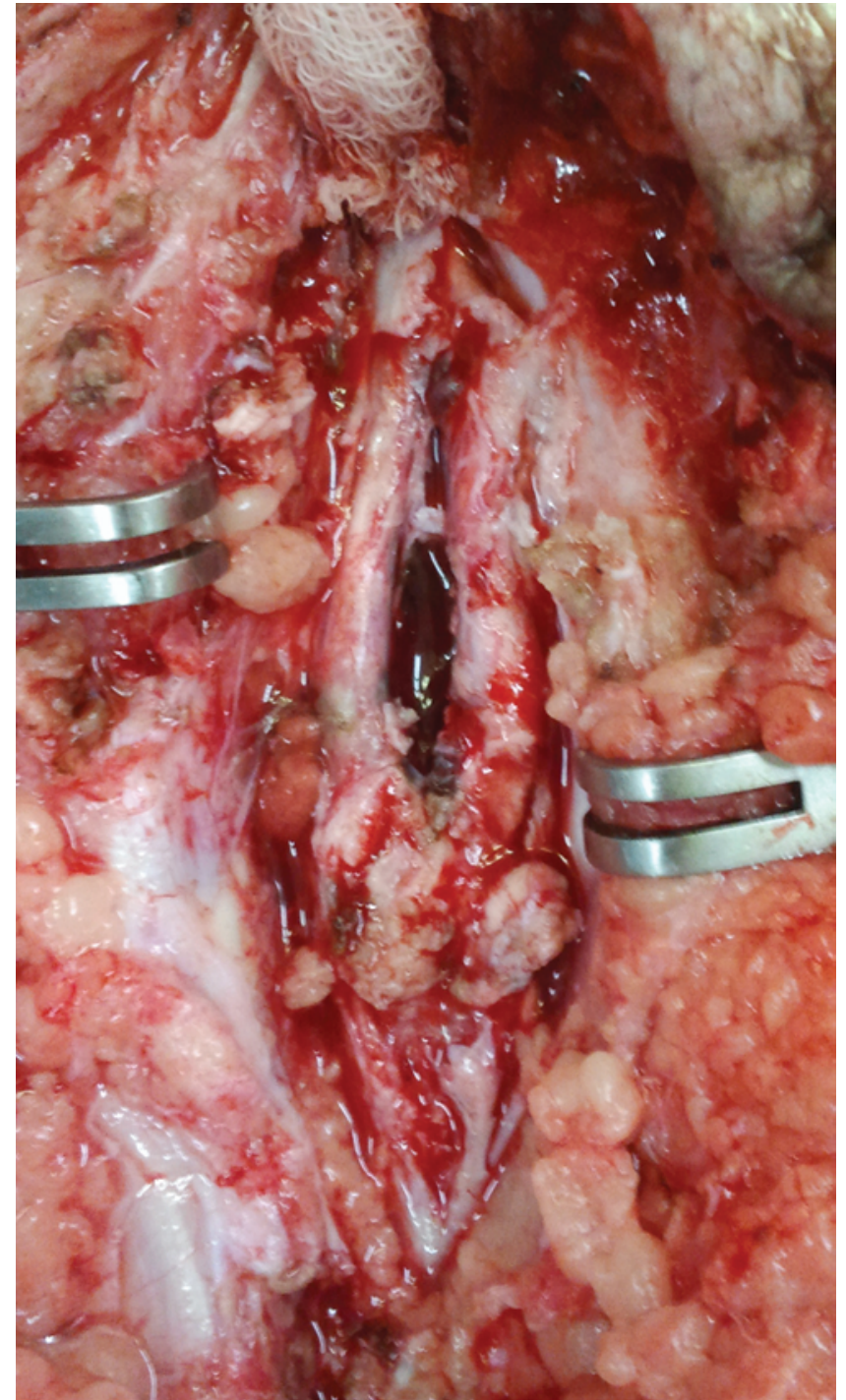

FIG. 3. Operative photograph obtained after excision of bony spur and lipo-MMC, and repair of the MMC. Figure is available in color online only.

fat, thus preventing the completion of the neural tube, and thereby tethering the spinal cord.

Closure of the neural tube, previously thought to be linear (like a zipper extending cranially and caudally), was hypothesized by Van Allen, in a multisite closure theory, to extend from several initiation sites along the craniocaudal neuraxis, with coordinated interaction of many waves of discontinuous neural tube closure. ${ }^{13}$ This investigator noted that MMC at any of multiple locations could be attributed to failure of fusion of any of the closures or their adjoining neuropores. Only a few cases of triple neural tube defects have been reported in the literature, mostly with discrete defects having intervening normal segments (Table 1). ${ }^{4,9,11,12}$ The associated CM-II and hydrocephalus in these cases could be explained by the unified theory of McLone, which is centered on defective apposition of neuroceles during neurulation, resulting in failure to maintain distension of the primitive ventricular system. ${ }^{5}$ This lack of distension alters the osteoinductive effect on endochondral bone formation, leading to a small posterior fossa and maldevelopment of the CSF pathway, causing hydrocephalus. Although the association of neurulation defects with $\mathrm{CM}$-II is well established, ${ }^{3}$ this theory is incompatible with preneurulation defects such as SCM, as elucidated by the unified theory of Pang.?

Various embryological hypotheses have been advocated to explain the etiology of different types of spinal dysraphism. ${ }^{2,3,10-12}$ These hypotheses, however, are not supported by experimental evidence. Nevertheless, the unified theory of Pang and the unified theory of McLone are incongruent with a missing link between gastrulation and neurulation. ${ }^{5,7}$ There has been only 1 report (by Singh et al. $)^{9}$ of triple dysraphism with SCM Type II in association with CM-II, evoking an enigmatic link between gastrulation (unified theory of Pang) and neurulation (unified theory of McLone). However, the discrete nature of the lesions in their case imply multiple embryogenetic defects. To our knowledge, the contiguity of MMC and lipo-MMC centered on SCM I and associated with CMII and hydrocephalus has not been reported yet. This can only be explained by contiguous errors at multiple stages of embryonic development-gastrulation, neurulation, and dysjunction.

In a previous work, Dhandapani et al. had suggested that faulty gastrulation adversely impacts the development of caudal cell mass during secondary neurulation. ${ }^{2}$ Although Solanki et al. speculated that pluripotent tissue of the caudal cell mass during secondary neurulation is responsible for these kinds of multiple dysraphic conditions ${ }^{10} \mathrm{CM}$-II due to secondary neurulation would certainly be unlikely. We hypothesize that this combination of contiguous triple spinal dysraphism with CM-II is probably because of either a cascade of cumulative contiguous developmental errors due to select abnormality of the neurenteric canal or a specific genetic vulnerability impacting all stages independently. The former possibility

TABLE 1. Summary of the reported cases of triple neural tube defects

\begin{tabular}{llllcc}
\hline \multicolumn{1}{c}{ Authors \& Year } & \multicolumn{1}{c}{ Types of Spinal Dysraphism } & Contiguous/ Discrete & CM-II & Hydrocephalus & SCM \\
\hline Mahalik et al., 2013 & Cervical \& dorsolumbar MMC, lumbar lipo-MMC & Discrete & Yes & Yes & No \\
\hline Singh et al., 2012 & Occipital encephalocele, upper dorsal MMC, \& lower dorsal SCM & Discrete & Yes & Yes & Type II \\
\hline Tekkök, 2005 & Parietal encephalocele, cervical \& dorsolumbar MMC & Discrete & Yes & Yes & No \\
\hline Srinivas et al., 2008 & Upper dorsal, lower dorsal, \& lumbar MMC & Discrete & Yes & Yes & No \\
\cline { 2 - 6 } & Occipital encephalocele, cervical \& dorsal MMC & Discrete & No & No & No \\
\hline Present study & Dorsolumbar SCM, MMC, \& lipo-MMC & Contiguous & Yes & Yes & Type I \\
\hline
\end{tabular}


can probably consolidate both the unified theory of Pang and the unified theory of McLone, with the inciting event being at the stage of gastrulation but impacting further development during and after neurulation. This theory of cumulative cascading contiguous developmental errors linking the unified theories of Pang and McLone needs further validation.

\section{References}

1. Detrait ER, George TM, Etchevers HC, Gilbert JR, Vekemans M, Speer MC: Human neural tube defects: developmental biology, epidemiology, and genetics. Neurotoxicol Teratol 27:515-524, 2005

2. Dhandapani S, Mehta VS, Sharma BS: "Horseshoe cord terminus" sans filum around a bone spur: a rare composite of faulty gastrulation with agenesis of secondary neurulation: case report. J Neurosurg Pediatr 12:411-413, 2013

3. Kapoor A, Dhandapani S, Singh P: The triad of holocord syringomyelia, Chiari malformation and tethered cord: amelioration with simple detethering-a case for revisiting traction hypothesis? Neurol India 62:708-709, 2014

4. Mahalik SK, Vaze D, Kanojia RP, Narasimhan KL, Rao KLN: Multiple neural tube defects may not be very rare. Childs Nerv Syst 29:609-619, 2013

5. McLone DG, Knepper PA: The cause of Chiari II malformation: a unified theory. Pediatr Neurosci 15:1-12, 1989

6. McLone DG, Mutluer S, Naidich TP: Lipomeningoceles of the conus medullaris, in Raimondi AJ (ed): Concepts in Pediatric Neurosurgery. Basel, Switzerland: Karger, 1983, pp 170-177

7. Pang D, Dias MS, Ahab-Barmada M: Split cord malformation: Part I: A unified theory of embryogenesis for double spinal cord malformations. Neurosurgery 31:451-480, 1992

8. Rossi A, Cama A, Piatelli G, Ravegnani M, Biancheri R, Tortori-Donati P: Spinal dysraphism: MR imaging rationale. J Neuroradiol 31:3-24, 2004
9. Singh N, Singh DK, Aga P, Singh R: Multiple neural tube defects in a child: A rare developmental anomaly. Surg Neurol Int 3:147, 2012

10. Solanki GA, Evans J, Copp A, Thompson DN: Multiple coexistent dysraphic pathologies. Childs Nerv Syst 19:376379,2003

11. Srinivas D, Sharma BS, Mahapatra AK: Triple neural tube defect and the multisite closure theory for neural tube defects: is there an additional site? Case report. J Neurosurg Pediatr 1:160-163, 2008

12. Tekkök IH: Triple neural tube defect—cranium bifidum with rostral and caudal spina bifida-live evidence of multi-site closure of the neural tube in humans. Childs Nerv Syst 21:331-335, 2005

13. Van Allen MI: Multisite neural tube closure in humans. Birth Defects Orig Artic Ser 30:203-225, 1996

\section{Disclosure}

The authors report no conflict of interest concerning the materials or methods used in this study or the findings specified in this paper.

\section{Author Contributions}

Conception and design: Dhandapani. Analysis and interpretation of data: Dhandapani. Drafting the article: both authors. Critically revising the article: Dhandapani. Reviewed submitted version of manuscript: both authors. Approved the final version of the manuscript on behalf of both authors: Dhandapani.

\section{Correspondence}

Sivashanmugam Dhandapani, Department of Neurosurgery, PGIMER, Sector 12, Chandigarh 160012, India. email: ssdhandapani.neurosurg@gmail.com. 